\title{
Voriconazole and fluconazole susceptibility of Candida isolates
}

\author{
RENÉ PELLETIER, LINE LORANGER, HÉLÈNE MARCOTTE and EMIDIO DE CAROLIS* \\ Laboratoire de Microbiologie, L'Hôtel-Dieu de Québec du Centre Hospitalier Universitaire de Québec, Québec \\ and *Anti-Infectives Research and Development Group, Pfizer Canada, Kirkland, Québec, Canada
}

\begin{abstract}
An adapted NCCLS M27-A method was used to evaluate the activity of voriconazole (VRC) and fluconazole (FLC) against 295 Candida isolates collected from 189 patients (including isolates from deep sites). Isolates included 186 C. albicans, 54 C. glabrata, 27 C. tropicalis, 14 C. parapsilosis, 6 C. krusei, 6 C. lusitaniae, 1 C. lypolytica and 1 C. sake. Forty-two isolates had reduced susceptibility to FLC (MIC $>8 \mathrm{mg} / \mathrm{L}$ ); $83.3 \%$ of these had VRC MICs $\leqslant 2 \mathrm{mg} / \mathrm{L}$ (9 of 11 C. albicans, 18 of 19 C. glabrata, 6 of 6 C. krusei, 2 of $2 C$. lusitaniae and 0 of 4 C. tropicalis), including $60 \%$ of isolates collected from deepseated infections. These results suggested that in the era of azole resistance, VRC has a promising antifungal activity for serious infections with Candida spp., including most species with low susceptibility to FLC and uncommonly isolated species.
\end{abstract}

\section{Introduction}

Invasive candida infection is a devastating illness [1] for which the effectiveness of initial empirical treatment is directly linked to patient outcome. Despite its universally recognised toxicity, amphotericin B was considered to be the cornerstone for successful therapy in disseminated candidosis [2]. The less toxic agent, fluconazole (FLC), offered an attractive alternative in the treatment of candidaemia and various invasive candida infections in non-neutropenic patients [3-5]. Major concerns about reduced FLC efficacy because of the increasing occurrence of Candida spp. potentially resistant to azole drugs [6-8] led to the development of new antifungal drugs. Voriconazole (VRC) exhibits fungicidal activity against a broad range of commonly encountered pathogenic yeasts including FLC-resistant species [9-11].

To assess the contemporary clinical value of VRC in the era of resistant yeasts, this study used an adapted NCCLS method to determine the susceptibility of recent Candida isolates, and compared the MICs of VRC and FLC.

Received 27 June 2001; revised version accepted 21 Nov. 2001.

Corresponding author: Dr R. Pelletier (e-mail: rene. pelletier@chuq.qc.ca).

\section{Materials and methods}

Clinical Candida isolates collected from Feb. 1997 to July 1999 and referred to the L'Hôtel-Dieu de Québec microbiology laboratory for antifungal susceptibility determination were included in the study. Each isolate was from a different patient or represented a distinct infection site or episode in the same patient. Candida isolates were categorised as invasive if a sterile or surgical collection procedure was used and classed as superficial in all other situations. Candida isolates were subcultured on CHROMagar Candida (CHROMagar, Paris, France) to ensure species purity and for final identification of $C$. albicans. Non-albicans isolates were further identified by ID 32C (bioMérieux, Marcyl'Etoile, France).

Pfizer Central Research Division (Groton, CT, USA) kindly provided voriconazole (UK-109,496) as $99.9 \%$ pure powder. Stock solution $(1600 \mu \mathrm{g} / \mathrm{ml})$ was first prepared by dissolving the powder in dimethyl sulphoxide (DMSO). A serial two-fold intermediary dilution was prepared by adding DMSO and RPMI 1640 (No. 04-525; Bio Whittaker, Walkersville, MD, USA) to stock solution according to NCCLS M27-A procedures [12]. After reconstitution with Candida suspension, VRC concentration ranged from $0.016 \mathrm{mg} / \mathrm{L}$ to $8 \mathrm{mg} /$ L. DMSO concentration was exactly $1 \%$ in each well including growth control. Fluconazole (Pfizer Canada, Pointe-Claire, QC, Canada) $2560 \mathrm{mg} / \mathrm{L}$ stock solution was prepared by dissolving powder in pure water. RPMI was then used to prepare two-fold dilutions. 
FLC final concentrations ranged from $0.125 \mathrm{mg} / \mathrm{L}$ to $64 \mathrm{mg} / \mathrm{L}$ when reconstituted with yeast suspension. Flat-bottomed microdilution plates (96-well tissue cell cluster, Costar 3599; Cambridge, MA, USA) were used to ensure accurate automatic reading. Wells from columns $1-10$ were dispensed with $100 \mu \mathrm{l}$ of serial dilutions of the respective antifungal drugs; $100 \mu \mathrm{l}$ of RPMI was dispensed in column 11 to serve as the growth control and $200 \mu \mathrm{l}$ of RPMI in column 12 for the sterility control. Individual Candida suspensions were prepared according to NCCLS M27-A methods and $100 \mu \mathrm{l}$ of each was dispensed in duplicate in two consecutive rows of the microtitration plate in columns $1-11$. After incubation for $48 \mathrm{~h}$ at $35^{\circ} \mathrm{C}$, a plate shaker (DSG Titertek; Flow Laboratories) was used to achieve a homogeneous turbidity of the growth in each well. Plates were then read with a spectrophotometer (Spectra II; SLT Labinstruments, Austria) set at $492 \mathrm{~nm}$. The MIC was defined as the lowest concentration of the drug that gave a $50 \%$ reduction in optical density when compared with the turbidity of the growth control well [13]. In cases where there was discrepancy between two rows of a tested isolate, the higher MIC was recorded. If there was discrepancy of more than one dilution the test was repeated. High off-scale MIC results were converted to the next higher concentration, and low off-scale results to the lowest tested concentration. C. parapsilosis ATCC 22019 and C. krusei ATCC 6258 were included in each testing run as quality control and MIC results were constantly in the predicted range for both antifungal drugs [14]. GraphPad Prism 3.0 (GraphPad Software, San Diego, CA, USA) was used to test MIC data correlation (Pearson method) and to compare Candida spp. susceptibility to VRC and FLC (two-sided $\chi^{2}$ test). A $\mathrm{p}<0.05$ was defined as statistically significant.

\section{Results and discussion}

Table 1 summarises the in-vitro activity of FLC and VRC against 295 Candida isolates collected from 189 patients, including 71 isolates (24\%) from deep-seated infections. In this experiment, the MIC90 values of FLC and VRC for Candida spp. were consistent with data obtained by other groups $[15,16]$. MICs for VRC were generally $1 \log _{10}$ lower than MICs for FLC, indicating that Candida isolates that were less susceptibile to FLC still expressed low MICs for VRC $[10,17]$. This was especially striking for well-recognised FLC-resistant species C. glabrata and C. krusei $[18,19]$. Previously reported bimodal MIC distribution for $C$. tropicalis was more pronounced for VRC results (Table 2) [20]. This could represent a testing artifact because this effect was less marked when an end-point reading was obtained from growth after the first $24 \mathrm{~h}$ (data not shown). Further clinical correlation is needed to evaluate the real significance of this phenomenon. Good correlation was achieved in comparing both antifungal results $\left(\mathrm{r}^{2}=0.315, \mathrm{p}<0.0001\right)$, indicating a systematic, proportional and predictable increased VRC activity for Candida species. Indeed, FLC-resistant isolates tend to produce proportionally higher VRC MICs, suggesting azole cross-resistance $[10,16,20$, 21].

Based on NCCLS interpretative guidelines, 42 Candida isolates (14.2\%) expressed reduced FLC susceptibility (MIC $>8 \mathrm{mg} / \mathrm{L}$ ), half of them being highly resistant $(\mathrm{MIC} \geqslant 64 \mathrm{mg} / \mathrm{L}) \quad$ [12]. Furthermore, 13 isolates $(61.9 \%)$ would not have been identified as FLCresistant if based on species identification only. This suggests the importance of antifungal susceptibility testing in therapeutic management. Despite reduced susceptibility in vitro, increasing FLC daily doses $(400-800 \mathrm{mg} /$ day $)$ has proved effective for isolates with MICs of 16 or $32 \mathrm{mg} / \mathrm{L}$ [13]. From a clinical point of view, any isolate with an FLC MIC $>8 \mathrm{mg} / \mathrm{L}$ has to be considered as having a high potential for nontherapeutic response to standard FLC dosage.

Although NCCLS methods can be used to determine antifungal activity of VRC, interpretation criteria have not been defined yet. At steady state, peak and trough

Table 1. In-vitro susceptibilities of Candida isolates $(\mathrm{mg} / \mathrm{L})$

\begin{tabular}{llcccc}
\hline $\begin{array}{l}\text { Species } \\
\text { (number of isolates) }\end{array}$ & $\begin{array}{l}\text { Antifungal } \\
\text { agent }\end{array}$ & MIC50 & MIC90 & Range & $\begin{array}{c}\text { Geometric } \\
\text { mean }\end{array}$ \\
\hline C. albicans (186) & Fluconazole & 0.25 & 2 & $\leqslant 0.125->64$ & 5.88 \\
& Voriconazole & $\leqslant 0.0156$ & 0.25 & $\leqslant 0.0156->8$ & 0.49 \\
C. glabrata (54) & Fluconazole & 8 & 32 & $\leqslant 0.125->64$ & 16.5 \\
& Voriconazole & 0.5 & 1 & $\leqslant 0.0156-8$ & 0.70 \\
C. krusei (6) & Fluconazole & 64 & $>64$ & $32->64$ & 64 \\
& Voriconazole & 0.5 & 2 & $0.25-2$ & 0.88 \\
C. lipolytica (1) & Fluconazole & 2 & 2 & 2 & 2 \\
& Voriconazole & $\leqslant 0.0156$ & 0.0156 & 0.0156 & 0.02 \\
C. lusitaniae (6) & Fluconazole & 0.5 & 64 & $0.5-64$ & 16.33 \\
& Voriconazole & $\leqslant 0.0156$ & 0.5 & $\leqslant 0.0156-0.5$ & 0.14 \\
C. parapsilosis (14) & Fluconazole & 1 & 1 & $0.25-4$ & 1 \\
& Voriconazole & $\leqslant 0.0156$ & 0.0625 & $\leqslant 0.0156-0.5$ & 0.06 \\
C. sake (1) & Fluconazole & 0.25 & 0.25 & 0.25 & 0.25 \\
& Voriconazole & 0.5 & 0.5 & 0.5 & 0.5 \\
C. tropicalis (27) & Fluconazole & 1 & $>64$ & $\leqslant 0.125->64$ & 16.48 \\
& Voriconazole & 0.25 & 16 & $\leqslant 0.0156->8$ & 4.51 \\
\hline
\end{tabular}


Table 2. Candida MIC distribution for voriconazole and fluconazole

\begin{tabular}{|c|c|c|c|c|c|c|c|c|c|c|c|c|c|c|c|}
\hline \multirow[b]{2}{*}{ Species } & \multirow[b]{2}{*}{$\mathrm{n}$} & \multicolumn{14}{|c|}{ Number $(\%)$ of isolates with MIC $(\mathrm{mg} / \mathrm{L})$ of } \\
\hline & & 0.0156 & 0.0313 & 0.0625 & 0.125 & 0.25 & 0.5 & 1 & 2 & 4 & 8 & 16 & 32 & 64 & 128 \\
\hline \multicolumn{16}{|l|}{ Voriconazole } \\
\hline C. albicans & 186 & 139 & 10 & 9 & 6 & 5 & 3 & 3 & 3 & 3 & 2 & 3 & & & \\
\hline C. krusei & 6 & & & & & 1 & 2 & 2 & 1 & & & & & & \\
\hline C. lipolytica & 1 & 1 & & & & & & & & & & & & & \\
\hline C. lusitaniae & 6 & 3 & & 1 & & 1 & 1 & & & & & & & & \\
\hline C. parapsilosis & 14 & 7 & 3 & 3 & & & 1 & & & & & & & & \\
\hline C. sake & 1 & & & & & & 1 & & & & & & & & \\
\hline C. tropicalis & 27 & 1 & 5 & 5 & 2 & 2 & 1 & & 2 & 1 & 2 & 6 & & & \\
\hline C. glabrata & 54 & 2 & & 6 & 7 & 10 & 16 & 10 & & 2 & 1 & & & & \\
\hline Total & 295 & 153 & $18(6.1)$ & $24(8.1)$ & $15(5.1)$ & $19(6.4)$ & $25(8.5)$ & $15(5.1)$ & $6(2.0)$ & $6(2.0)$ & $5(1.7)$ & $9(3.1)$ & & & \\
\hline Cumulative \% & & 51.9 & 58.0 & 66.1 & 71.2 & 77.6 & 86.1 & 91.2 & 93.2 & 95.2 & 96.9 & 100 & & & \\
\hline \multicolumn{16}{|l|}{ Fluconazole } \\
\hline C. albicans & 186 & & & & 74 & 69 & 17 & 5 & 5 & 5 & & & 2 & 3 & 6 \\
\hline C. krusei & 6 & & & & & & & & & & & & 2 & 3 & 1 \\
\hline C. lipolytica & 1 & & & & & & & & 1 & & & & & & \\
\hline C. lusitaniae & 6 & & & & & & 4 & & & & & & 1 & 1 & \\
\hline C. parapsilosis & 14 & & & & & 2 & 3 & 8 & & 1 & & & & & \\
\hline C. sake & 1 & & & & & 1 & & & & & & & & & \\
\hline C. tropicalis & 27 & & & & & 2 & 9 & 8 & 2 & 1 & 1 & & 1 & & 3 \\
\hline C. glabrata & 54 & & & & 1 & & & 1 & 1 & 10 & 22 & 12 & 3 & 2 & 2 \\
\hline Total & 295 & & & & $75(25.4)$ & $74(25.1)$ & $33(11.2)$ & $22(7.5)$ & $9(3.1)$ & $17(5.8)$ & $23(7.8)$ & $12(4.1)$ & $9(3.1)$ & $9(3.1)$ & $12(4.1)$ \\
\hline Cumulative $\%$ & & & & & 25.4 & 50.5 & 61.7 & 69.2 & 72.8 & 78.0 & 85.8 & 89.8 & 92.9 & 95.9 & 100 \\
\hline
\end{tabular}


serum concentrations of VRC when given at $200 \mathrm{mg}$ orally twice daily have ranged from $2.1 \mathrm{mg} / \mathrm{L}$ to $4.8 \mathrm{mg} / \mathrm{L}$ and $1.4 \mathrm{mg} / \mathrm{L}$ to $1.8 \mathrm{mg} / \mathrm{L}$, respectively. Blood levels in children were consistent with those observed in adults [22]. VRC pharmacokinetics suggest that adequate serum levels are available to treat infecting fungal organisms with VRC MICs $\leqslant 2 \mathrm{mg} / \mathrm{L}$ effectively.

Thirty-five (83.3\%) isolates with reduced susceptibility to FLC had VRC MIC $\leqslant 2 \mathrm{mg} / \mathrm{L} \quad(\mathrm{p}=0.006)$. They included $9(82 \%)$ of 11 C. albicans $(\mathrm{p}=0.02), 18$ (95\%) of 19 C. glabrata, 6 of 6 C. krusei, 2 of 2 C. lusitaniae and none of 4 C. tropicalis. Furthermore, $7 \%$ of deep-seated infections were caused by Candida isolates with FLC MICs $>8 \mathrm{mg} / \mathrm{L}$; interestingly, $60 \%$ of these isolates demonstrated low VRC MICs $(\mathrm{p}<$ 0.001). Candida isolates expressing high FLC MICs and low VRC MICs were C. glabrata or C. krusei. Furthermore, three of nine $C$. albicans in this category were from clinically resistant oropharyngeal candidosis in patients who were HIV-positive.

Unlike Candida spp. isolated in the first years of clinical use of FLC, this study investigated the in-vitro susceptibility of isolates collected in recent years, reflecting a more clinically relevant situation with regards to azole resistance and therapeutic options [2, 23-25]. The increasing rate of invasive infection caused by Candida isolates that are not susceptible to FLC is a major concern for clinicians [7, 24, 26, 27]. Despite the possibility of cross-resistance, VRC has the advantages of favourable pharmacokinetics and proportionally increased potency and can overcome the therapeutic limitations of FLC.

The results of this study confirm VRC as a promising antifungal triazole with an expanded spectrum of activity against $C$. albicans, C. glabrata, C. krusei, $C$. parapsilosis and $C$. lusitaniae. They also supply some insight into the in-vitro susceptibility of less common species such as C. lipolytica and $C$. sake. In-vitro data, together with its pharmacokinetics, clinical efficacy and safety profile, suggest that VRC is a viable therapeutic choice for empirical therapy in severe candida infections.

This work was supported by Pfizer Canada. Results were presented in May 2000 at the ISHAM meeting in Buenos Aires.

\section{References}

1. Wey SB, Mori M, Pfaller MA, Woolson RF, Wenzel RP. Hospital-acquired candidemia. The attributable mortality and excess length of stay. Arch Intern Med 1988; 148: 2642-2645.

2. Edwards JE, Bodey GP, Bowden RA et al. International Conference for the Development of a Consensus on the Management and Prevention of Severe Candidal Infections. Clin Infect Dis 1997; 25: 43-59.

3. Rex JH, Bennett JE, Sugar AM et al. A randomized trial comparing fluconazole with amphotericin B for the treatment of candidemia in patients without neutropenia. Candidemia
Study Group and the National Institute of Allergy and Infectious Diseases Mycoses Study Group. $N$ Engl J Med 1994; 331: $1325-1330$.

4. Phillips P, Shafran S, Garber G et al. Multicenter randomized trial of fluconazole versus amphotericin B for treatment of candidemia in non-neutropenic patients. Canadian Candidemia Study Group. Eur J Clin Microbiol Infect Dis 1997; 16: 337-345.

5. Rex JH, Walsh TJ, Sobel JD et al. Practice guidelines for the treatment of candidiasis. Clin Infect Dis 2000; 30: 662-678.

6. Richards MJ, Edwards JR, Culver DH, Gaynes RP. Nosocomial infections in medical intensive care units in the United States. National Nosocomial Infections Surveillance System. Crit Care Med 1999; 27: 887-892.

7. Pfaller MA, Jones $\mathrm{RN}$, Doern $\mathrm{GV}$ et al. International surveillance of blood stream infections due to Candida species in the European SENTRY Program: species distribution and antifungal susceptibility including the investigational triazole and echinocandin agents. SENTRY Participant Group (Europe) Diagn Microbiol Infect Dis 1999; 35: 19-25.

8. Marr KA, White TC, van Burik J-AH, Bowden RA. Development of fluconazole resistance in Candida albicans causing disseminated infection in a patient undergoing marrow transplantation. Clin Infect Dis 1997; 25: 980-910.

9. Marco F, Pfaller MA, Messer SA, Jones RN. Antifungal activity of a new triazole, voriconazole (UK-109,496), compared with three other antifungal agents tested against clinical isolates of filamentous fungi. Med Mycol 1998; 36: 433-436.

10. Ruhnke M, Schmidt-Westhausen A, Trautmann M. In vitro activities of voriconazole (UK-109,496) against fluconazolesusceptible and -resistant Candida albicans isolates from oral cavities of patients with human immunodeficiency virus infection. Antimicrob Agents Chemother 1997; 41: 575-577.

11. McGinnis MR, Pasarell L, Sutton DA, Fothergill AW, Cooper $\mathrm{CR}$, Rinaldi MG. In vitro evaluation of voriconazole against some clinically important fungi. Antimicrob Agents Chemother 1997; 41: 1832-1834.

12. National Committee for Clinical Laboratory Standards. Reference method for broth dilution antifungal susceptibility testing of yeasts; approved standards. NCCLS document M27A. Wayne, PA, National Committee for Clinical Laboratory Standards. 1997.

13. Rex JH, Pfaller MA, Walsh TJ et al. Antifungal susceptibility testing: practical aspects and current challenges. Clin Microbiol Rev 2001; 14: 643-658.

14. Barry AL, Pfaller MA, Brown SD et al. Quality control limits for broth microdilution susceptibility tests of ten antifungal agents. J Clin Microbiol 2000; 38: 3457-3459.

15. Pfaller MA, Messer SA, Hollis RJ et al. In vitro susceptibilities of Candida bloodstream isolates to the new triazole antifungal agents BMS-207147, Sch 56592, and voriconazole. Antimicrob Agents Chemother 1998; 42: 3242-3244.

16. Marco F, Pfaller MA, Messer S, Jones RN. In vitro activities of voriconazole (UK-109,496) and four other antifungal agents against 394 clinical isolates of Candida spp. Antimicrob Agents Chemother 1998; 42: 161-163.

17. Barry AL, Brown SD. In vitro studies of two triazole antifungal agents (voriconazole [UK-109,496] and fluconazole) against Candida species. Antimicrob Agents Chemother 1996; 40: 1948-1949.

18. Koul A, Vitullo J, Reyes G, Ghannoum M. Effects of voriconazole on Candida glabrata in vitro. J Antimicrob Chemother 1999; 44: 109-112.

19. Ghannoum MA, Okogbule-Wonodi I, Bhat N, Sanati H. Antifungal activity of voriconazole (UK-109,496), fluconazole and amphotericin B against hematogenous Candida krusei infection in neutropenic guinea pig model. J Chemother 1999; 11: $34-39$.

20. Nguyen MH, Yu CY. Voriconazole against fluconazolesusceptible and resistant candida isolates: in-vitro efficacy compared with that of itraconazole and ketoconazole. $J$ Antimicrob Chemother 1998; 42: 253-256.

21. Cuenca-Estrella M, Diaz-Guerra TM, Mellado E, Monzon A, Rodriguez-Tudela JL. Comparative in vitro activity of voriconazole and itraconazole against fluconazole-susceptible and fluconazole-resistant clinical isolates of Candida species from Spain. Eur J Clin Microbiol Infect Dis 1999; 18: 432-435.

22. Hegener P, Troke PF, Fätkenheuer G, Diehl V, Ruhnke M. Treatment of fluconazole-resistant candidiasis with voricona- 
zole in patients with AIDS. AIDS 1998; 12: 2227-2228.

23. Sobel JD, Ohmit SE, Schuman $\mathrm{P}$ et al. The evolution of Candida species and fluconazole susceptibility among oral and vaginal isolates recovered from human immunodeficiency virus (HIV)-seropositive and at-risk HIV-seronegative women. $J$ Infect Dis 2001; 183: 286-293.

24. Nguyen MH, Peacock JE, Morris AJ et al. The changing face of candidemia: emergence of non-Candida albicans species and antifungal resistance. Am J Med 1996; 100: 617-623.

25. Goldman M, Cloud GA, Smedema M et al. Does long-term itraconazole prophylaxis result in in vitro azole resistance in mucosal Candida albicans isolates from persons with advanced human immunodeficiency virus infection? The National Institute of Allergy and Infectious Diseases Mycoses Study Group. Antimicrob Agents Chemother 2000; 44: 1585-1587.

26. Pfaller MA, Jones RN, Doern GV et al. Bloodstream infections due to Candida species: SENTRY antimicrobial surveillance program in North America and Latin America, 1997-1998. Antimicrob Agents Chemother 2000; 44: 747-751.

27. Lewis RE, Klepser ME. The changing face of nosocomial candidemia: epidemiology, resistance, and drug therapy. Am J Health Syst Pharm 1999; 56: 525-535. 